\title{
Paleontología, ciencia, patrimonio y futuro
}

Gloria Cuenca-Bescós | Aragosaurus-IUCA, Dpto. Ciencias de la Tierra, Universidad de Zaragoza

URL de la contribución <www.iaph.es/revistaph/index.php/revistaph/article/view/4166>

\begin{abstract}
¿Cuál es el papel del paleontólogo o paleontóloga en los proyectos de investigación e intervención patrimonial? ¿Qué formación específica ha de tener? La paleontología es la ciencia que permite conocer la vida en el pasado y cómo ha ido evolucionando. El tándem tierra-vida ha hecho cambiar y evolucionar el clima y el paisaje de nuestro planeta. Los seres humanos vivimos en este planeta porque, entre otros factores geológicos -terrestres y extraterrestres-, la vida y la evolución lo han hecho posible.
\end{abstract}

Ponderamos este conocimiento mediante el estudio de los fósiles, objetos que reciben este nombre por estar enterrados en los sedimentos y en las rocas que forman la corteza de la tierra. El registro fósil es un recurso excepcional para conocer la historia de la vida y los paleontólogos somos los investigadores que sacamos la información de estos fósiles. Esto respondería a la pregunta de cuál es el papel del paleontólogo o paleontóloga en los proyectos de investigación patrimonial. He quitado la palabra intervención puesto que un paleontólogo puede, además de excavarlos, investigar los fósiles ya extraídos en anteriores excavaciones/intervenciones, depositados e inventariados y almacenados en una institución pública, sin ánimo de lucro y que tenga un proyecto a largo plazo de protección patrimonial. La institución puede ser museo, universidad, centro de investigación, centro de interpretación local, etc. Es preciso que cumpla con unos requisitos para asegurar la conservación y adecuado almacén de los fósiles, así como la posibilidad, en función del tamaño de la institución, de investigar y divulgar en paleontología, evolución, reconstrucciones ambientales, y todo el conocimiento que se desarrolla a partir del estudio de los fósiles.

El papel del paleontólogo es entonces fundamental a la hora de analizar los vestigios de la vida en el pasado de la Tierra. Las especies que han existido, su evolución y diversificación y la riqueza o abundancia de las especies en el pasado; la (paleo) biodiversidad y su evolución en el tiempo. Aplicar los estudios paleontológicos a los problemas que preocupan a la humanidad actual como el cambio climático, el futuro de los seres humanos, la protección de la naturaleza, entre otros muchos.

\section{Por qué es importante la protección del patrimonio paleontológico}

La relevancia de las instituciones que guardan el patrimonio paleontológico es precisamente su labor de registro e inventariado, así como la restauración y conservación que permite poner a disposición de esta y futuras generaciones de investigadores el material paleontológico. Los fósiles han estado guardados en su roca desde hace cientos, miles y millones de años por lo que la protección de los mismos tiene que continuar la casi "inmortal" labor que la tierra ha realizado. La protección del patrimonio paleontológico consiste en perpetuar esta "inmortalidad" de la vida del pasado.

Por otra parte, el patrimonio paleontológico para las futuras generaciones podrá ser estudiado con nuevas ideas y técnicas mejores que descubrirán aspectos de la vida en el pasado inimaginables hasta ahora. En mi campo de la paleontología de microvertebrados en medios continentales, no había antes del SEM (escáner electrónico de barrido), manera de observar los detalles de la superficie oclusal de los molares de los micromamíferos como son las marcas de abrasión en los roedores o las crestas en las cúspides de los diminutos molares de los multituberculados. El SEM, TEM y otra microscopía de alta resolución permite además de ver detalles morfológicos, descubrir los elementos atómicos que componen huesos y los dientes fósiles y descubrir que no son solo fosfato cálcico. Además las nuevas técnicas permitirán 
a debate El marco legal para la protección del patrimonio paleontológico. ¿Qué pasa en tu comunidad?

reconocer mejor el estado de conservación de los fósiles para afrontar necesidades de futuras restauraciones y óptimo almacenamiento. Las nuevas técnicas de extracción de ADN antiguo pueden encontrar trazas en fósiles bien conservados, no muy antiguos y lo mismo puedo añadir en el caso de los análisis isotópicos.

El patrimonio paleontológico bien guardado e inventariado permitirá además analizar la evolución de la biodiversidad en nuestro planeta a través del análisis de los fósiles de diversas instituciones. Para ello es fundamental que, además de la labor de una institución particular, se cree una red que permita conocer lo que se conserva en varias instituciones a escala global, regional, nacional e internacional. Los "big data" así obtenidos permitirán saber cuál es el papel del ser humano en la conservación de la naturaleza, cuándo empieza el ser humano a ser afectado por el medio ambiente y viceversa. Los programas de conservación de las especies son cada vez más conscientes de la importancia de las grandes colecciones de los museos, que en algunos casos llevan más de 200 años guardando, almacenando, inventariando y estudiando materiales biológicos. Los programas de conservación basados por ejemplo en el Ecological Niche Modeling así lo indican. Algunos autores resaltan la importancia de las grandes colecciones paleontológicas para extraer un modelo de las condiciones abióticas del nicho paleoecológico adecuado para cada especie. Es una técnica que requiere una correlación entre la información estratigráfica, geográfica y geológica proporcionada por la presencia espacial y temporal de la especie y el conjunto de condiciones ambientales en cada área donde la especie estuvo presente. Estas técnicas podrán en el futuro ayudar a discernir el futuro de la humanidad con el cambio climático y cómo afecta este a las especies que viven con nosotros en nuestro planeta.

\section{Un apunte sobre la importancia del patrimonio paleontológico}

Como parte de nuestro pasado, el patrimonio paleontológico atrae mucho al público en general. Pienso que la paleontología tiene un papel intelectual en una sociedad cada vez más liberada del trabajo manual y que está ansiosa por conocer, explorar, investigar. En mis clases en la Universidad de la Experiencia, cuento la evolución humana y las técnicas de datación relativa con fósiles de microvertebrados (mi especialidad) a más de 100 alumnos, dos veces al año. Esto quiere decir que 200 personas, ya adultas, en edad de jubilación, que acuden a clases porque quieren saber más, representan todos los años desde 2005 al menos, lo que en mi opinión es el futuro de la humanidad: pasión por saber, pasión por conocer. Porque nuestro cerebro necesita alimento una vez que hemos "cumplido" con la parte material. De hecho tenemos muchos más alumnos en los cursos de la Universidad de la Experiencia de los que tenemos en grado o máster de Geología en la Universidad de Zaragoza.

Con esto quiero decir que veo que las personas llegan a una edad de jubilación con una mente lúcida y ávida de conocimientos y que investigar en cómo era la vida en el pasado es una tarea a la que pueden acceder si existen instituciones guardianas del patrimonio paleontológico, como los museos y si se abren al público y hay profesionales que pueden guiarles y enseñarles.

Las ciencias ambientales y sociales deberían tener en cuenta esta nueva faceta de una población humana, cada vez más importante en la sociedad actual, con una mente madura y lúcida y a una edad en la que pueden todavía desarrollar y explorar el conocimiento de la vida en el pasado de la mano de los fósiles. Es posible que a la pregunta de ¿Cuál es el papel del paleontólogo o paleontóloga en los proyectos de investigación e intervención patrimonial? ¿Qué formación específica ha de tener? Debamos añadir que el papel del paleontólogo es fundamental en los proyectos de investigación e intervención patrimonial pero que no hay límite de edad si está formado convenientemente. Para finalizar creo que la del paleontólogo debe ser una formación en grado en Ciencias, pueden ser Geológicas, Ciencias de la Tierra, Ciencias Naturales o simplemente Geología y Biología, con una especialización de Master en Paleontología. 